\title{
Post-traumatic syringomyelia: a review of the literature
}

\author{
A Biyani MS MCh (Orth), ${ }^{1}$ W S El Masry FRCS (ED) ${ }^{2}$ \\ ${ }^{1}$ Orthopaedic Registrar, Arrowe Park Hospital, Upton, Wirral, L49 5PE; ${ }^{2}$ Consultant in \\ Spinal Injuries, and Medical Director, The Midlands Centre for Spinal Injuries, Robert \\ Jones and Agnes Hunt Hospital, Oswestry, Shropshire, SY10 7AG; Senior Lecturer in \\ Orthopaedics, Keele University, England.
}

The need for increased awareness and a high index of suspicion for post traumatic syringomyelia is emphasised. Early clinical diagnosis confirmed by MRI and early treatment can avert or minimise the potentially devastating effects of post traumatic syringomyelia. The regular and frequent follow up of the patient on a yearly or alternate year basis to monitor the patient with spinal injury for this complication, as well as other complications, is the best way to ensure that post traumatic syringomyelia is diagnosed and managed early in order to avoid further disability.

Keywords: spine; spinal cord injury; post-traumatic; syrinx; syringomyelia; meningeal fibrosis; cystic myelopathy; MRI.

\section{Introduction}

Syringomyelia is a relatively infrequent, but potentially disastrous complication of spinal cord injury. A high cervical syringomyelia can be life threatening due to its rapid progression and upward extension into the brainstem. Since Barnett's ${ }^{1}$ description in 1966 , post-traumatic syringomyelia (PTS) is being increasingly recognised. Unfortunately, the existence of PTS as an entity has not yet been widely appreciated, particularly by orthopaedic surgeons. PTS has been confused with conditions such as Hansen's disease, ${ }^{2}$ and lack of awareness of this complication of spinal cord injury has resulted in missed diagnosis, ${ }^{3}$ and incorrect treatment, such as ulnar nerve decompression at the elbow. ${ }^{4}$

\section{Incidence}

The reported incidence of PTS is between 0.3 to $3.2 \%$, with a mean of $1.3 \% .^{5}$ In a retrospective study of 815 spinal cord in-

Correspondence: W S El Masry.

This work is part of an MChOrth thesis submitted by the first author to the University of Liverpool, England, 1993. jured patients, we noted a $3.4 \%$ overall incidence of PTS. ${ }^{4}$ Edgar and Quail ${ }^{6}$ estimated the true incidence of post-traumatic cystic myelopathy to be between 5 and $8 \%$. The incidence of PTS is higher in dorsal spine in some series, ${ }^{3,4,7,8}$ and higher in cervical spine in others. ${ }^{9,10}$

The interval between spinal injury and syringomyelia is variable, and can occur from 2 months $^{3,11}$ to several years after the injury. The patients with incomplete cord injury developed PTS after longer interval compared to patients with complete spinal cord injury in the series of Lyons et al,${ }^{10}$ who reported the onset of PTS after a mean of 101 months in nine patients with incomplete lesions as compared to 39 months in 12 patients with neurologically complete lesions. However, Vernon et al and El Masry and Biyani ${ }^{4}$ could not find any significant difference in the time of onset of syringomyelia between the patients with complete and incomplete cord injuries. Syringomyelia in a previously neurologically intact patient with a vertebral fracture is rare. Van den Bergh $^{12}$ reported development of syringomyelia in a patient who initially had complete neurological recovery after spinal cord injury. 
It has been suggested that the incidence of syringomyelia in complete lesions is similar to incomplete lesions, and there is no correlation with the severity of original cord injury. ${ }^{2,5,13}$ Backe et al ${ }^{14}$ reported similar incidence of post-traumatic spinal cord cysts between the patients with ASIA (American Spinal Injury Association) motor index of less than 50 or more than 50 . However, the incidence of syringomyelia following complete cord injury was two to three times higher than incomplete spinal cord injury in other series. ${ }^{4,6-8,10}$ Rossier et al ${ }^{9}$ reported $3.9 \%$ and $2.4 \%$ incidence of PTS following complete and incomplete spinal cord injury respectively. In their series, syrinx formation was higher in complete tetraplegia and incomplete paraplegia. The literature is thus replete with confusing information on the incidence of PTS, which may be due to several factors including the type of initial spinal cord injury treatment, differing rehabilitation programmes and lack of well designed epidemiological studies.

Post-traumatic syringomyelia has been reported to occur following either surgical $^{15-17}$ or conservative ${ }^{18}$ treatment. Unfortunately, many larger studies ${ }^{2,3,7-10,19,20}$ do not mention the mode of initial treatment of the spinal cord injury. There are no large studies in the literature comparing the incidence of syringomyelia in conservatively and surgically treated spinal cord injury population.

\section{Pathogenesis}

Exact pathogenesis of PTS has not been elucidated. Several theories have been put forward, but the most attractive and widely accepted theory has been proposed by Williams et al ${ }^{21}$ who recognised two steps in the pathogenesis of PTS, namely formation of cavity followed by its enlargement and extension. Initially, a cavity forms by liquefaction of the cord tissue or hematoma at the site of the spinal cord injury. Microinfarcts $^{21}$ as well as lysosomal and other cellular enzymes ${ }^{22}$ may also play an important role in the liquefaction process and cyst formation. Additionally, arachnoiditis or arachnoid adhesions due to the healing process may tether the traumatised spinal cord. Upon spinal flexion and extension, adhesions of the anterior and posterior parts of the cord may lead to upward and downward movement of the posterior portion of the cord independent of the anterior portion, thus initiating a cavity within the spinal cord by traction-distension. ${ }^{8,21}$ Arachnoiditis may also facilitate cavitation by producing ischaemia or directing cerebrospinal fluid from the subarachnoid space in to the cord cavity, possible by transmural fluid migration. ${ }^{23}$

The cavitation is most frequently initiated at the level of the fracture, ${ }^{8}$ in the grey matter between the dorsal horns and posterior columns, which is a relatively avascular zone between the dorsal and ventral arterial supply and is also relatively deficient in connective tissue., ${ }^{7,21}$ The cavity may subsequently break down and communicate with the central canal. Rarely, the intramedullary cavity may be associated with intradural arachnoid cysts. ${ }^{15}$

Expansion and cephalo-caudal extension of the cyst occurs by transmission of the distensile pressure pulses within the epidural veins due to coughing, sneezing, straining or exercises. Williams et $a l^{21}$ have described two phenomena affecting intracordal fluid movements. The first mechanism, so called 'slosh' involves vertical pulsatile surge of the pressure and fluid movement within the cord. 'Slosh' occurs as a result of increased epidural venous pressure and it breaks down the areas of structural weakness in the cord, thus leading to extension of the syrinx both proximally and distally. Septations are indicative of substantial filling of the syrinx under tension, and 'slosh' movements in this situation are of relatively shorter wavelength, extending between adjacent septa. ${ }^{23}$ 'Suck' is the second mechanism involving partial subarachnoid block, in which the fluid is initially forced up with increased epidural venous pressure but is returned only slowly, thus creating a pressure gradient across the subarachnoid partial block, with negative pressure caudal to it. The positive pressure proximal to the block leads to extension of the syrinx proximally. Acute distension of the syrinx has been reported to occur 
due to intracavitary haemorrhage, so called Gowers' syringeal haemorrhage, but this is rare. $^{24}$

The role of internal gibbus, posttraumatic kyphoscoliosis and instability has not, so far, been specifically evaluated in the initiation or propagation of the syrinx. Similarly, the effects of scarring and arachnoiditis secondary to surgical treatment of the spinal injury are not well understood. Why some patients develop syringomyelia as early as 2 months after injury, while others may not develop PTS until several years later, is also not clear.

\section{Pathology}

On ultrastructural study of post-traumatic syringes obtained from two patients who underwent surgical cordectomy, Reddy et $a l^{25}$ demonstrated that the syrinx is lined largely by flattened ependymal cells, thought to represent the remnants of central canal ependyma. Clusters of disorganised ependymal cells caudal to the syrinx cavity were seen in their specimens, supporting their hypothesis that the central canal either gives rise to syrinx at least partially or it is subsequently incorporated into the syrinx. Presence of collagen has been reported in the syrinx lining by Oakley et al, ${ }^{26}$ but this was not confirmed by Reddy et al. ${ }^{25}$ Sherman et $a l^{27}$ microscopically examined two spinal cord autopsy specimens and demonstrated that abnormally high MRI signals around the syrinx were due to gliosis, which is an astrocytic response to adjacent tissue damage. Williams \& Timperley ${ }^{28}$ noted the severity of gliosis to be directly related to the duration of syrinx formation and severity of the forces on its wall. Gliosis is therefore maximally present circumferentially and proximally, in response to the distending upward forces. ${ }^{29}$ Reddy et $a l^{25}$ concluded that these changes represent the nonspecific sequelae of distensile forces within the syrinx cavity based on their findings of similarity of structural appearance of a post-traumatic syrinx to that of communicating syringomyelia and periventricular changes associated with hydrocephalus.

\section{Clinical features}

Pain is the commonest initial symptom of PTS in most series. ${ }^{3,4,9,30}$ It may be a dull aching and constant, or stabbing, burning and intermittent in nature. Pain is usually located at or above the site of the original spinal injury, and may radiate to the neck or the upper limbs. Rarely, the pain may be referred to areas below the spinal injury e.g. abdomen or the lower limb. ${ }^{3,9}$ Pain is usually increased by straining, coughing or sneezing. Rossier et $a l^{9}$ noted that the pain was worse in sitting rather than lying position in some of their patients. This may be attributed to the gravitional forces on the lower part of the cyst, resulting in focal stretching of the spinal cord. ${ }^{13}$

The syrinx usually extends superiorly more than inferiorly, ${ }^{13}$ leading to an ascending sensory level, which is the second most common presentation after pain ${ }^{3,4,9}$ and is almost always present, unless PTS is detected at a very early stage by routine MRI scanning. In a series of 30 patients with PTS, Rossier et al $^{9}$ noted dissociated sensory loss between pain and proprioception in 28 patients and between pain and touch in 19 patients. They suggested that the touch sensation is less frequently involved in PTS due to mediation of its fibres in anterior and lateral as well as dorsal columns. The pain sensation is most commonly impaired, but the temperature sense is impaired in $50 \%$ of cases, while vibration and proprioception may be normal. ${ }^{7}$ The sensory loss may be patchy and may exhibit daily variations. ${ }^{3}$ The deficit may be unilateral ${ }^{3}$ or bilateral. ${ }^{9}$

Increased motor weakness is the third most common feature of PTS. Several authors ${ }^{3,9,31}$ have noted that motor weakness is rarely a sole clinical feature of PTS. Exclusive motor weakness occurred in one out of nine patients of Anton \& Schweigel $^{7}$ and three out of 40 patients of Vernon et al. ${ }^{3}$ Motor weakness is commonly associated with an ascending sensory level and loss of deep tendon reflexes. Loss of deep tendon reflexes in the upper limbs is the earliest sign of PTS, and can usually be elicited before the onset of the symptoms. ${ }^{30,31}$ Deep tendon reflexes may also be lost in lower limbs in up to $50 \%$ patients with PTS. ${ }^{21}$ 
Hyperhidrosis may be present in the patients with PTS usually above the level of the cord injury. ${ }^{21,30}$ Presence of hyperhidrosis below the level of previous spinal injury may indicate extension of the syrinx proximally and distally. ${ }^{32}$ Increased spasticity, ${ }^{14}$ decreased spaticity, ${ }^{33}$ hypertension ${ }^{17}$ and neuropathic joints ${ }^{2}$ are other less common features of PTS. Diaphragmatic paralysis is a life threatening complication that may occur due to a syrinx extending proximal to $\mathrm{C} 4$ level. Trigeminal nerve involvement and Horner's syndrome may also be associated. ${ }^{7}$ Rarely, a partial Horner's syndrome may be present, which may demonstrate anisocoria only. ${ }^{33}$

Urinary involvement has been previously described in association with PTS in one patient, ${ }^{34}$ but this was considered to be an aetiological factor by increasing the venous pressure rather than a result of PTS. On the other hand, downward extension of the syrinx may render the urinary bladder hyporeflexic, and this may present with increased difficulty in voiding as the sole presenting feature or in combination with other clinical features of PTS. ${ }^{4}$ Rarely bowel dysfunction may be caused by a syrinx extending to the conus, which may necessitate a colostomy. ${ }^{33}$

\section{Diagnosis}

Various diagnostic imaging techniques have been used in the past for the diagnosis of PTS. These include now obsolete invasive techniques such as oil myelography, ${ }^{35}$ cyst puncture and oil myelography ${ }^{36}$ and gas myelography. ${ }^{37}$ The introduction of CT scan was a significant step forward in the diagnosis of PTS. ${ }^{38,39}$ Lyons et al ${ }^{10}$ performed the scans immediately, $5-8 \mathrm{~h}$ and $24 \mathrm{~h}$ after the contrast injection. They recommended at least one scan to include the posterior cranial fossa to assess the fourth ventricle. Griffith \& McCormick ${ }^{2}$ and Lyons et al ${ }^{10}$ advocated CT myelography. The cord often appears smaller on CT scan than on gas myelography due to lack of gravitational filling. ${ }^{37,40}$ The length of the syrinx and the area of the maximum cyst dilatation as well as any communication with the fourth ventricle are better delineated by gas myelography, ${ }^{37}$ because the imaging table used for gas myelography can be tilted up or downwards, which is not possible with CT scan. However, communication between post-traumatic syrinx and fourth ventricle is rare. ${ }^{26}$ However, gas myelography is an invasive technique, it needs a general anaesthetic to perform, and it cannot differentiate a post-traumatic cystic myelopathy from a cystic tumour which may rarely coexist in a spinal cord injured patient. ${ }^{37}$

Magnetic resonance imaging (MRI) is currently the preferred mode of investigation for the diagnosis of PTS. It provides noninvasive, multiplanar, high resolution images of the posterior cranial fossa, the spinal cord and the syrinx.$^{41,43} \mathrm{~T} 1$ and $\mathrm{T} 2$ weighted spin echo sequences in sagittal planes and $\mathrm{T} 1$ images in axial planes have been recommended for demonstration of the syrinx and its extent. ${ }^{43}$ Low signal of the cyst fluid contrasts with intermediate strength signal of the spinal cord in $\mathrm{T} 1$ images, which provide better anatomical resolution due to less motion artefacts. Increased signal intensity due to gliosis may be seen on T1 and T2 weighted images in the areas surrounding the syrinx, ${ }^{17,27}$ and circumferential gliotic bands may give a beaded appearance to the syrinx on the longitudinal scans. ${ }^{44}$ T2 images are also helpful in detecting associated intrinsic cord disease or demyelination. ${ }^{45}$

The syrinx is often eccentrically located, and the reported mean of this maximum cavity diameter on MRI scan is $6.6 \mathrm{~mm}$ to $7.1 \mathrm{~mm} .{ }^{27,43}$ It can extend over several vertebral segments the mean reported length varying from 3.6 to 10.1 segments. . $^{40,27,43}$ An intriguing feature of syringomyelia is an extraordinary lack in the correlation between the size of the syrinx and the intensity of the deficits. ${ }^{4,33}$

Backe et $a l^{14}$ demonstrated spinal cord cysts at the level of the previous spinal cord trauma on routine MRI scanning in 32 of 63 patients $(51 \%)$, who were either asymptomatic or were tolerating their symptoms. None of these patients presented with ascending myelopathy. Thus, demonstration of a post-traumatic spinal cord cyst on MRI does not constitute a clinically significant syrinx. The natural history of these small asymptomatic cysts is difficult to 
ascertain from the study of Backe et al,${ }^{14}$ as it was concluded after a relatively short follow up of 1.6 years. Tobimatsu et al $^{46}$ and Williams ${ }^{23}$ believe that the term 'syringomyelia' should be applied only when the cavity extends to two or more vertebral body segments.

MRI is useful in detecting progression of PTS. It is also valuable in selecting the site of myelotomy and shunt placement, and assessing the outcome of the surgical treatment of PTS (Figs 1 and 2). Its drawbacks include implant related artefacts, and difficulty in differentiating PTS from myelomalacia ${ }^{47}$ and from tumour associated syringomyelia. Finally, MRI has also been shown to be inferior to intraoperative sonography in detecting septations and small additional cysts. ${ }^{17}$ Use of nonferrogenous implants, gadolinium enhanced images, and newer MRI scanners may be able to overcome these problems.

The role of intraoperative real time sono-

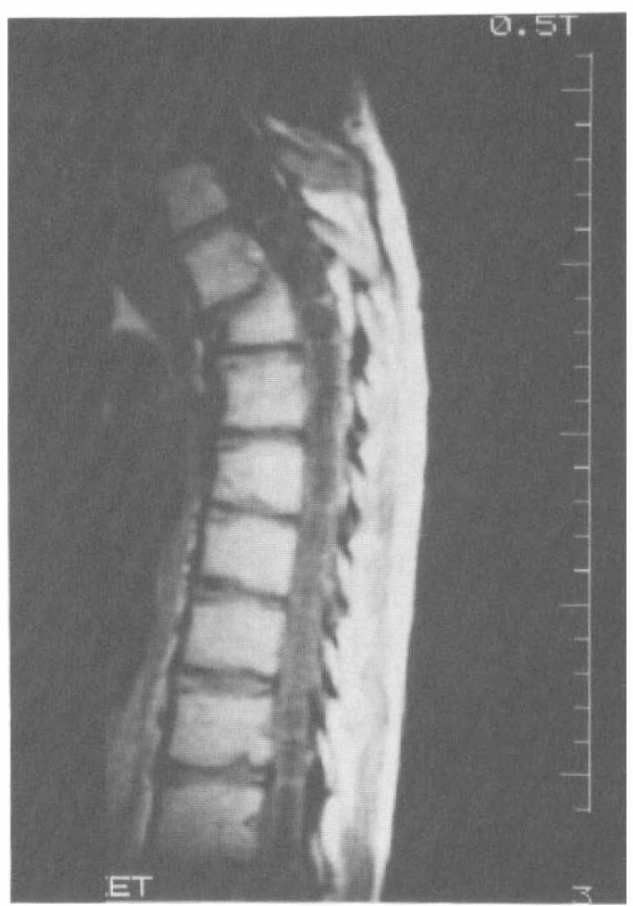

Figure 1 High dorsal fracture with syringomyelia extending upwards and downwards. This patient had previously been treated by a drainage tube to the widest part of the syrinx.

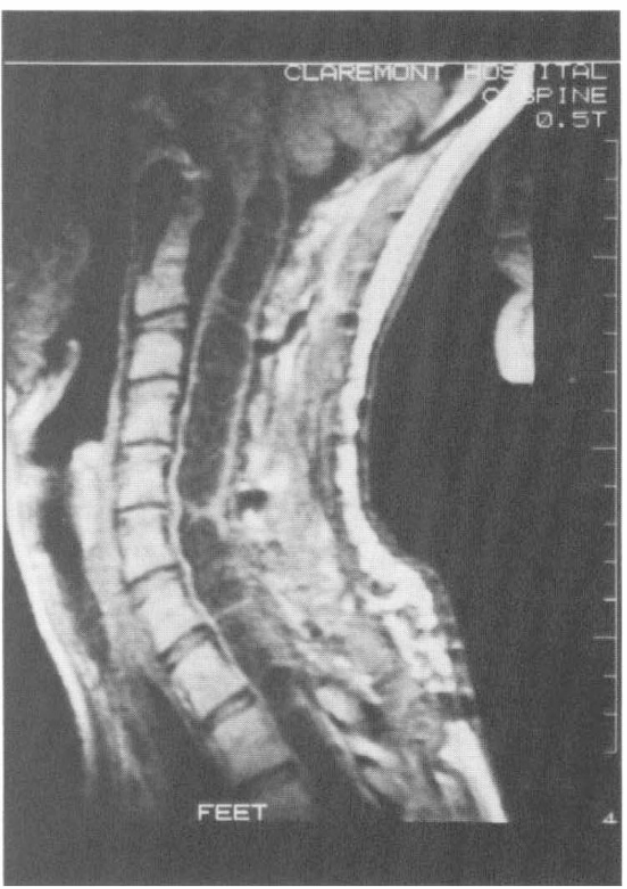

Figure 2 Cervical spine of the same patient as in Figure 1. The scan extends as high as $\mathrm{C} 1$. This young woman had no motor losses highlighting the possible discrepancy between the size of the PTS and the absence of symptoms but a syrinx of this size is clearly life threatening.

graphy in PTS has not been extensively investigated, but it has been successfully utilised to localize cystic cavities. ${ }^{15}$ Gebarski et $a l^{17}$ noted that intraoperative sonography was superior to delayed CT myelography as well as MRI in detecting septations. They also considered intraoperative sonography to be useful in selecting the site of myelotomy and placement of a shunt, as well as for intraoperative confirmation of adequate decompression of the cyst.

Electrophysiological studies have a limited value in the diagnosis and monitoring of syringomyelia. Needle electromyography and $\mathrm{F}$ wave studies of the median and the ulnar nerve have poor sensitivity and specificity for the diagnosis of syringomyelia. Central motor conduction time calculated from the scalp and the spine motor evoked potentials is the only useful electrophysical 


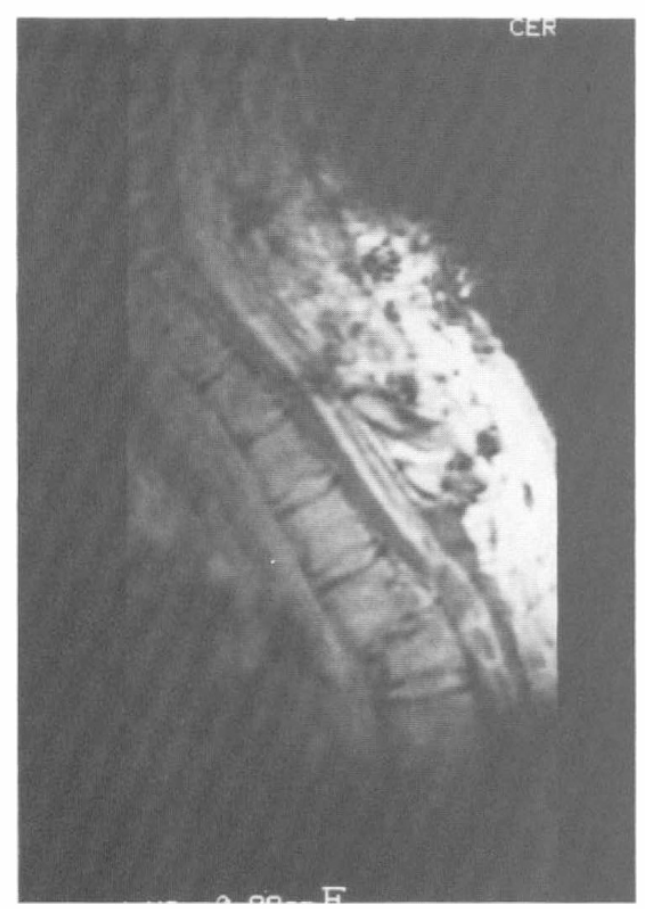

Figure 3 Postoperative MRI scan including the level of the fracture. Same case as Figures 1 and 2. Notice the collapse of the upper syrinx with widening of the subarachnoid space ventral to the cord. At the site of decompressive laminectomy the CSF pathways can be seen to be patent past the site of the artificial cisterna magna behind the fracture. The cord at the site of the injury shows the persisting cavitation. This is sometimes referred to as a primary cyst and its persistance suggests that the mechanisms are different from the extensive syringomyelia which was previously present above and below.

test ${ }^{48}$ but its usage has not become popular, and it has only limited application as an adjunct to MRI.

\section{Treatment}

The natural history of PTS has not been fully defined and can be variable. It is not clear how small spinal cord cysts behave and when they the are likely to become symptomatic. Some authors ${ }^{3,9}$ believe that all the patients on conservative treatment of spinal cord cysts will eventually show signs of progression and neurological deterioration, if followed up for long enough. On the other hand, the neurological status may remain unchanged for months or years despite slow progression of the cyst, ${ }^{9}$ or rarely spontaneous resolution may occur. ${ }^{10,49}$

It has been recommended that nonprogressive asymptomatic PTS may be treated conservatively by close observation and serial MRI scanning. ${ }^{8,14,16}$ However, Lyons et $a l^{10}$ recommended surgical treatment for all the patients with PTS involving the cervical cord, to minimise the risk of respiratory failure secondary to rapid progression of the syrinx.

Surgical treatment is recommended for progressive syringomyelia with neurological deterioration. Cord transection is feasible only in complete lesions. ${ }^{10,50}$ Needle aspiration of the syrinx or myelotomy ${ }^{51}$ often has poor results because of its inability to maintain continued drainage of the syrinx. However, Levy et $a^{52}$ recommended percutaneous drainage followed by MRI scanning to confirm the diagnosis and causal relationship of PTS in patients with atypical clinical features by demonstrating the resolution of the symptoms. They also concluded that MRI evidence of complete evacuation of the syrinx by percutaneous drainage indicates the absence of significant loculations or septations within the cavity, and therefore, a good outcome following a shunting procedure can be predicted.

Good results have been reported following a syringo-subarachnoid shunt, ${ }^{16,53,54}$ but the shunt frequently gets blocked, with recurrence of syringomyelia. ${ }^{10,49}$ Lyons et $a l^{10}$ advocated a syringo-peritoneal shunt for thoraco-lumbar syrinx, and syringocisternal shunt for high thoracic or cervical syringomyelia, as the shunt blockage is less compared to a syringo-subarachnoid shunt. Some authors ${ }^{19,51,55}$ have reported a syringoperitoneal shunt to be better than a syringosubarachnoid shunt. However, Umbach and Heilporn $^{5}$ noted that no one shunting procedure has been clearly shown to be superior to others.

Williams ${ }^{8}$ recommended that the syrinx should be shunted to a low pressure system such as the pleural or the peritoneal cavity for effective drainage, and an internal posttraumatic gibbus or arachnoiditis, if present, should be dealt with at the same time. According to him, abolition of a pressure 
gradient and free flow of the cerebrospinal fluid are vital factors in minimising the risk of recurrence of syringomyelia. Vascularised omental transposition has recently been performed for myelomalacia and meningeal adhesions with or without cystic changes, with mixed short term results, ${ }^{23}$ and no long term studies have yet been published in the English literature.

Edgar \& Quail $^{6}$ described a procedure called laser myelopiccolotomy with a view to obviate the need for a shunt tube. Multiple drainage sites were created by making multiple puncture holes throughout the cyst using laser. However, in their preliminary experience with 18 cases, they had a $50 \%$ revision rate to dural scarring which obstructed the myelotomy sites.

Septated syringomyelia presents problems in ensuring complete drainage of all the chambers. Huewel et $a l^{56}$ recently reported satisfactory preliminary results in 11 patients with septated syringomyelia treated by using flexible neuroendoscope, which allows perforation of septa under vision.

The results of surgery for PTS are favourable. In our series, ${ }^{4} 22$ patients treated surgically for PTS had 13 good (neurologically improved) six fair (neurologically stable), and three poor (neurologically worse) results after a mean follow up of 3 years (range 6 months to 15 years). Relief of pain, often dramatic, is almost always observed, and improvement in motor weakness is another fairly consistent finding of surgical treatment of PTS. , $^{4,19}$ Sensory recovery has been poor in several studies, ${ }^{7,9,19,53}$ but Lyons et al ${ }^{10}$ and El Masry \& Biyani $^{4}$ reported postoperative sensory improvement in $91 \%$ and $72 \%$ of patients respectively. Umbach and Heilporn ${ }^{5}$ noted that surgery has no effect on spasticity of dysaesthetic pain, but in our series ${ }^{4}$ spasticity improved in $80 \%$ patients. According to Williams ${ }^{33}$ decompressive surgery for syringomyelia often improves the bladder function in patients with syringomyelia induced bladder dysfunction. However, the spasm may intensify as the lower syrinx heals.

Grant et $a l^{57}$ and Pillay et $a l^{20}$ recommended measurement of the size of the syrinx on pre and postoperative MRI scans to determine the prognosis of PTS. The measurements of absolute cord size and of the syrinx in the preoperative MRI axial cuts are, in our experience, subject to considerable error, and do not seem to have any significant prognostic value. In our experience ${ }^{4}$ and that of Williams, ${ }^{33}$ there is no correlation between the size of the syrinx on the preoperative MRI scans and severity of neurological deficit. On the other hand, like Pillay et al, ${ }^{20}$ we noted good correlation $(85 \%)$ between reduction in the size of the syrinx on postoperative MRI scan and the result of the surgical treatment. ${ }^{4}$ Complete drainage of the syrinx, was however, not necessary in our study for a good clinical outcome, which could be obtained even by mild to moderate reduction in the size of the syrinx.

In summary, there is need for increased awareness, and a high index of suspicion for PTS is emphasised. Early diagnosis by MRI, and early treatment can avert or minimise the potentially devastating effects of PTS.

\section{Acknowledgements}

We are grateful to Mr Bernard Williams, Consultant Neurosurgeon, Smethwick, Birmingham, Drs I McCall and V Pullicino, Consultant Radiologists at the Robert Jones and Agnes Hunt Orthopaedic and District Hospital, Oswestry for their help and support. Illustrations were kindly provided by Mr B Williams, FRCS

\section{References}

1 Barnett HJM, Botterell EH, Jousse AT, Wynne Jones M (1966) Progressive myelopathy as a sequel to traumatic paraplegia. Brain 89: 159-174.

2 Griffiths ER, McCormick CC (1981) Post-traumatic syringomyelia (Cystic myelopathy). Paraplegia 19: 81-88.

3 Vernon JD, Silver JR, Ohry A (1982) Post-traumatic syringomyelia. Paraplegia 20: 339-364.

4 El Masry WS, Biyani A (1994) The incidence, management and outcome of post-traumatic syringomyelia. Submitted for publication. 
5 Umbach I, Heilporn A (1991). Review article: Post-spinal cord injury syringomyelia. Paraplegia 29: 219-221.

6 Edgar R, Quail P (1994) Progressive post-traumatic cystic and non-cystic myelopathy. Br J Neurosurg 8: 7-22.

7 Anton HA, Schweigel JF (1986) Posttraumatic syringomyelia: The British Columbia experience. Spine 11: 865-868.

8 Williams B (1990) Post-traumatic syringomyelia, an update. Paraplegia 28: 296-313.

9 Rossier AB, Foo D, Shillito J, Dyro FM (1985) Post-traumatic cervical syringomyelia. Incidence, clinical presentation, electrophysiological studies, syrinx protein, and results of conservative and operative treatment. Brain 108: 439-461.

10 Lyons BM, Brown DJ, Calvert JM et al (1987) The diagnosis and management of posttraumatic syringomyelia. Paraplegia 25: 340-350.

11 Yarcony GM, Sheffler LR, Smith J et al (1994) Early onset posttraumatic cystic myelopathy complicating spinal cord injury. Arch Phys Med Rehabil 75: 102-105.

12 Van den Bergh R (1991) Pathogenesis and treatment of delayed post-traumatic syringomyelia. Acta Neurochirurgica 110: 82-86.

13 Quencer RM, Green BA, Eismont FJ (1983) Posttraumatic spinal cord cysts: Clinical features and characterization with metrizamide computed tomography. Radiology 146: 415-423.

14 Backe HA, Betz RR, Mesgarzadeh M et al (1991) Post-traumatic spinal cord cysts evaluated by magnetic resonance imaging. Paraplegia 29: 607-612.

15 Andrews BT, Weinstein PR, Rosenblaum ML, Barbaro NM (1988) Intradural arachnoid cysts of spinal canal associated with intramedullary cysts. J Neurosurg 68: 544-549.

16 Eismont FJ, Green BA, Quencer RM (1984) Post-traumatic spinal-cord cyst. A case report. J Bone Joint Surg Am 66A: 614-618.

17 Gebarski SS, Maynard FW, Gabrielsen TO et al (1985) Posttraumatic progressive myelopathy. Radiology 157: $378-385$.

18 Bradway JK, Kavanagh BF, Houser OW (1986) Post-traumatic spinal cord cyst. A case report. J Bone Joint Surg Am 68A: 932-933.

19 Vernon JD, Silver JR, Symon L (1983) Post-traumatic syringomyelia: The results of surgery. Paraplegia 21: 37-46.

20 Pillay PK, Awad IA, Littler JR, Hahn JF (1991) Surgical management of syringomyelia: a five year experience in the era of magnetic resonance imaging. Neurol Res 13: 3-9.

21 Williams B, Terry AF, Francis Jones HW, McSweeney T (1981) Syringomyelia as a sequel to traumatic paraplegia. Paraplegia 19: 67-80.

22 Kao C, Chang LW (1977) The mechanism of spinal cord cavitation following spinal cord transection. Part I. A correlated histo-chemical study. J Neurosurg 46: 197-209.

23 Williams B (1992) Pathogenesis of post-traumatic syringomyelia (editorial). Br J Neurosurg 6: 517-20.

24 Perot P, Feindal W, Lloyd-Smith D (1966) Hematomyelia as a complication of syringomyelia: Gowers' syringeal hemorrhage. J Neurosurg 25: 447-451.

25 Reddy KKV, Bigio MRD, Sutherland GR (1989) Ultrastructure of the human posttraumatic syrinx. J Neurosurg 71: 239-243.

26 Oakley JC, Ojeman GA, Alvord ED Jr (1981) Post traumatic syringomyelia. Case report. J Neurosurg 55: 276-281.

27 Sherman JL, Barkovich AJ, Citrin CM (1987) The MR appearance of syringomyelia: New observations. AJR 148: $381-391$

28 Williams B, Timperley WR (1976) Three cases of communicating syringomyelia secondary to midbrain gliomas. J Neurol Neurosurg Psychiatry 40: 80-88.

29 Lee BCP, Zimmerman RD, Manning JJ, Deck MDF (1985) MR imaging of syringomyelia and hydromyelia. AJR 144: 1149-1156.

30 Dworkin GE, Stass WE (1985) Posttraumatic syringomyelia. Arch Phys Med Rehabil 66: 329-331.

31 Watson N (1981) Ascending cystic degeneration of the cord after spinal cord injury. Paraplegia 19: 89-95.

32 Stanworth PA (1982) The significance of hyperhidrosis in patients with post-traumatic syringomyelia. Paraplegia 20: 282-287.

33 Williams B (1994) Personal communication.

34 Umbach I, Heilporn A (1988) Evaluation of post-traumatic cervical syringomyelia: Case report. Paraplegia 26: $56-61$.

35 Dichiro G, Fischer RL (1964) Contrast radiography of the spinal cord. Arch Neurol 125-143.

36 Kendall B, Symon L (1973) Cyst puncture and endomyelography in cystic tumours of the spinal cord. Br J Radiol 46: 198-204.

37 Rossier AB, Foo D, Naheedy MH et al (1983) Radiography of posttraumatic syringomyelia. AJNR 4: 637-640.

38 Dichiro G, Axelbaum SP, Schellinger D et al (1975) Computerized axial tomography in syringomyelia. N Engl J Med 292: 13-16.

39 Aubin ML, Vignaud J, Jardin C, Bar D (1981) Computed tomography in 75 clinical cases of syringomyelia. AJNR 2: 199-204. 
40 Seibert CE, Dreisbach JN, Swanson WB et al (1981) Progressive post-traumatic cystic myelopathy: Neuroradiologic evaluation. AJR 136: 1161-1165.

41 Kokmen E, March WR, Baker HI Jr (1985) Magnetic resonance imaging in syringomyelia. Neurosurg 17: 267-270.

42 Paushter DM, Modic MT, Masaryk TJ (1985) Magnetic resonance imaging of the spine: Application and limitations. Radiol Clin N Am 23: 551-562.

43 Dowling RJ, Tress BM (1989) MRI-The investigation of choice in syringomyelia? Australas Radiol 33: 337-343.

44 Williams B (1980) On the pathogenesis of syringomyelia: A review. J R Soc Med 73: 798-806.

45 Betz RR, Gelman AJ, DeFillip GJ et al (1987) Magnetic resonance imaging (MRI) in the evaluation of spinal cord injured children and adolescents. Paraplegia 25: 92-99.

46 Tobimatsu H, Nihei R, Kimura T et al (1991) Magnetic resonance imaging of spinal cord injury in chronic stage (in Japanese). Rinsho Seikei Geka (Clin Orth Surg) 26: 1173-1182.

47 Pojunas K, Williams AL, Daniels DL, Haughton VM (1981) Syringomyelia and hydromyelia: magnetic resonance evaluation. Radiology 153: 679-683.

48 Little JW, Robinson LR, Goldstein B et al (1992) Electrophysiological findings in post-traumatic syringomyelia: implications for clinical management. J Am Paraplegia Soc 15: 44-52.

49 Birbamer G, Buchberger W, Felber S et al (1993) Spontaneous collapse of posttraumatic syringomyelia: serial magnetic resonance imaging. Euro Neurol 33: 378-381.

50 Durward QJ, Rice GP, Ball MJ et al (1982) Selective spinal cordectomy: clinicopathological correlation. J Neurosurg 56: 359-367.

51 Peerless SJ, Durward QJ (1983) Management of syringomyelia: a pathological approach. Clin Neurosurg 30: 531-536.

52 Levy R, Rosenblatt S, Russell E (1991) Percutaneous drainage and serial magnetic resonance imaging in the diagnosis of symptomatic posttraumatic syringomyelia: Case report and review of the literature. Neurosurgery 29: 429-434.

53 Shannon N, Symon L, Logue V et al (1981) Clinical features, investigations and treatment of post-traumatic syringomyelia. J Neurol Neurosurg Psychiatry 44: 35-42.

54 Tator CH, Meguro K, Rowed DW (1982) Favourable results with syringo-subarachnoid shunts for treatment of syringomyelia. J Neurosurg 56: 517-523.

55 Barbaro NM, Wilson CB, Gutin PH, Edwards MSB (1984) Surgical treatment of syringomyelia. Favourable results with syringoperitoneal shunting. J Neurosurg 61: 531-538.

56 Huewel N, Perneczky A, Urban V, Fries G (1992) Neuroendoscopic technique for the operative treatment of septated syringomyelia. Acta Neurochir Suppl Wien 54: 59-62.

57 Grant R, Hadley DM, Lang D et al (1987) MRI measurement of the syrinx size before and after operation. $J$ Neurol Neurosurg and Psychiatry 50: 1685-1687. 